J. Biosci., Vol. 22, Number 2, March 1997, pp 143-147. (C) Printed in India.

\title{
Nucleotide sequence of a cucumber chloroplast proline tRNA
}

\author{
SHAILAJA HANDE and C JAYABASKARAN* \\ Department of Biochemistry, Indian Institute of Science, Bangalore 560 012, India
}

MS received 12 June 1996; revised 18 November 1996

\begin{abstract}
The nucleotide sequence of a proline tRNA (anticodon UGG) from cucumber chloroplasts has been determined. The sequence is: pAAGGAUGUAGCGCAGCUUCADAGCGCA $\Psi U U G U U U G G N \Psi F A C A A A A U m^{7}$ GUCACGGGT $\Psi C A A A U C C U G-$ UCAUCCUUACCA $A_{\mathrm{OH}}$. It shows $93 \%$ homology with spinach chloroplast tRNA ${ }^{\text {Pro }}$ (UGG) and $72 \%$ homology with bean mitochondrial tRNA ${ }^{\text {Pro }}$ (UGG), the other two known plant organellar tRNAs ${ }^{\text {Pro }}$.
\end{abstract}

Keywords. Nucleotide sequence; cucumber chloroplast; proline tRNA.

\section{Introduction}

Chloroplasts contain their own protein-synthesizing apparatus. All tRNAspecies involved in chloroplast protein synthesis are believed to be encoded by chloroplast DNA. Although detailed studies on sequence analyses of the completely sequenced chloroplast genomes of four land plants, namely tobacco (Shinozaki et al 1986), rice (Hiratsuka et al 1989), liverwort (Ohyama et al 1986) and maize (Maier et al 1995) have revealed the structures of approximately 30 to 32 different tRNA genes in each of these chloroplast genomes, knowledge of their RNA sequences including modified nucleosides is still poor. The information about occurrence and position of modified nucleotides in the primary structures have been of particular interest because several modified nucleotides have been shown to be associated with a range of biological functions, such as maintenance of translational fidelityand efficiency, codon usage and tRNA-protein interactions (Persson 1993). Only a few plant chloroplast tRNAs have been sequenced so far. They are tRNA ${ }^{\text {Glu }}$ (UUC) and tRNA ${ }^{\text {Gln }}$ (UUG) from Hordeum vulgäre, tRNA ${ }^{\text {lle }}$ (GAU) from maize, tRNA ${ }^{\text {Leu }}$ (CAA), tRNA ${ }^{\text {Leu }}(\mathrm{UAA}), \mathrm{tRNA}^{\mathrm{Leu}}(\mathrm{UAG})$ from soybean, tRNA Phe $(\mathrm{GAA}), \mathrm{tRNA}^{\mathrm{Leu}}$ (CAA), tRNA $^{\text {Leu }}(\mathrm{UAA}), \mathrm{tRNA}^{\mathrm{Leu}}(\mathrm{UAG})$ and $\mathrm{tRNA}^{\text {Trp }}(\mathrm{CCA})$ from bean and $\mathrm{tRNA}^{\text {phe }}(\mathrm{GAA})$, tRNA $^{\text {Ile }}$ (GAU), tRNA ${ }^{\text {Ile }}$ (NAU), tRNA ${ }^{\text {Leu }}$ (UAG), tRNA ${ }^{\text {Met }}$ (CAU), tRNA ${ }^{\text {Pro }}$ (UGG), tRNA $^{\text {Thr }}$ (GGU), tRNA ${ }^{\text {Trp }}$ (CCA) and tRNA ${ }^{\text {Val }}$ (UAC) from spinach (Sprinzl et al 1989). In order to understand primary and secondary structures of plant chloroplast tRNAs, a detailed study of cucumber chloroplast tRNAs has been undertaken. Here we present the nucleotide sequence of a cucumber chloroplast proline tRNA.

\section{Materials and methods}

\subsection{Materials}

Cucumber seeds were obtained from National Seed Corporation, Bangalore, Acryla mide, DEAE-cellulose and nuclease PI were purchased from Sigma Chemicals Co. USA.

\footnotetext{
*Corresponding author (Fax, 91-80-3341814, 3341683; Email, cjb@biochem.iisc.ernet.in).
} 
Cellulose thin layer plates were obtained from Mechery-Nagel, Germany. T4 polynuc leotide kinase was purchased from New England BioLabs. $\left[\gamma^{-32} \mathrm{P}\right]$ ATP was obtained from Board of Radiation and Isotope Technology, Mumbai.All other chemicals used were of analytical grade.

\subsection{Purification of cucumber chloroplast tRNA ${ }^{\text {Pro }}$}

Total cucumber chloroplast tRNA was isolated from cucumber cotyledons as de scribed previously (Jayabaskaran and Hande 1995). Cucumber chloroplast tRNA ${ }^{\text {Pro }}$ was purified by the combined use of RPC-5 column chromatography and twodimensional Polyacrylamide gel electrophoresis (PAGE) procedure (Jayabaskaran and Puttaraju 1993).

\subsection{Sequencing of tRNA}

To determine the primary structure of the tRNA ${ }^{\text {Pro }}$, we used single hit hydrolysis in deionized formamide followed by $\mathrm{T} 4$ polynucleotide kinase $\left[{ }^{32} \mathrm{P}\right]$-labelling, PAGE separation of labelled fragments and enzymatic analysis of the end nucleotides by one-dimensional thin-layer chromatography (TLC) as previously described (Jayabas karan and Puttaraju 1993). Two-dimensional TLC was employed for the identification of modified nucleotides using the solvents isobutyric acid: $25 \% \mathrm{NH}_{4} \mathrm{OH}: \mathrm{H}_{2} \mathrm{O}$ $(66: 1: 33 \mathrm{v} / \mathrm{v} / \mathrm{v})$ in the first dimension and isopropanol: Cone. $\mathrm{HCl}: \mathrm{H}_{2} \mathrm{O}(70: 15: 15$ $\mathrm{v} / \mathrm{v} / \mathrm{v}$ ) in the second dimension (Keith 1995).

\subsection{Computer analysis}

Sequence comparisons were carried out using the GCG software package (Genetics Computer Group) on Micro VAXII VMS version $4 \cdot 6$ operating system.

\section{Results and discussion}

While purification of isoleucine isoacceptor tRNAs from cucumber total chloroplast tRNA by RPC-5 column chromatography followed by identification of individual fractions for isoleucine-accepting activity and two-dimensional PAGE of the tRNA ${ }^{\text {Ile }}$ enriched fractions (Hande 1992), one of the 19 major spots well separated on the 2D-gel was identified by amino acylation to be a tRNA ${ }^{\text {Pro }}$ (data not shown) and its twodimensional PAGE mobility corresponds to tRNA $^{\text {Pro }}$ reported earlier (Jayabaskaran and Hande 1995). The tRNA was further purified by denaturing 15\% PAGE and subjected to the sequence analysis. The sequence of this tRNA in the clover leaf form is shown in figure 1. Its length is 76 nucleotides including 7 modified nucleotides. These modified nucleotides are: one each of $\mathrm{D}, \mathrm{m}^{7} \mathrm{G}, \mathrm{T}$ and $\mathrm{N}$ (unknown modified nucleoside) and three $\Psi$.

We have compared all 11 known tRNAs ${ }^{\text {Pro }}$ (UGG) sequences with the cucumber tRNA $^{\text {Pro }}(\mathrm{UGG})$. As shown in table 1 it is very similar to spinach chloroplast tRNA ${ }^{\text {Pro }}$ (UGG) (93\% homology). It shows $72 \%$ homology to bean mitochondrial tRNA ${ }^{\text {Pro }}$ (UGG) but is considerably less homologous with $S$. cerevisiae mitochondrial tRNA ${ }^{\text {Pro }}$ 


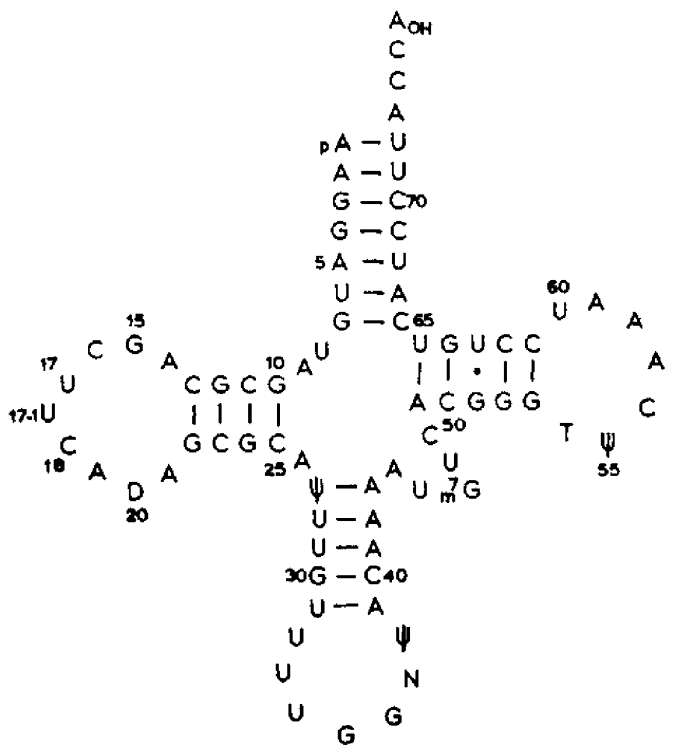

Figure 1. Secondary structure of cucumber chloroplast tRNA ${ }^{\text {Pro }}(\mathrm{UGG})$. The numbering system of nucleotides is according to Sprinzl et al (1989). N (37): unidentified modified nucleotide.

Table 1. Similarity comparison between the cucumber chloroplast tRNA ${ }^{\text {Pro }}$ (UGG) and its homologues in other species and organelles. All these tRNA sequences can be found in Sprinzl et al (1989).

\begin{tabular}{lc}
\hline Species & Percentage \\
\hline Spinacia oleracea (chloro) & 93 \\
Phaseolus vulgaris \{mito) & 72 \\
Bacillus subtilis & 69 \\
Mycoplasma mycoid & 68 \\
Salmonella typhimurium & 64 \\
Phage T4 & 59 \\
Saccharomyces cerevisiae & 49 \\
Saccharomyces cerevisiae (mito) & 44 \\
Halobacterium volcanii & 44 \\
Phage T5 & 43 \\
Torulopsis utilis & 43 \\
\hline
\end{tabular}

(UGG) (44\% homology). This higher homology with plant organelle tRNAs ${ }^{\text {Pro }}$ sug gests that tRNAs ${ }^{\text {Pro }}$ from these organelles in plants may be similar with respect to their structure-function relationship. It should be noted that the cucumber $\operatorname{tRNA}^{\text {Pro }}$ (UGG) exhibits greater homology with eubacterial (64-69\% homology) than with its archaebacterial counterparts. 
It has been shown previously upon fractionation of cucumber chloroplast tRNA population by two-dimensional PAGE (Jayabaskaran and Hande 1995) that cucumber chloroplast contained only one $\mathrm{tRNA}^{\text {Pro }}$. Fractionation and identification of chloro plast tRNAs of bean, spinach maize and Euglena on two-dimensional gels has also revealed one proline tRNA (Mubumbila et al 1980). Moreover, it is also known from four completely sequenced chloroplast genomes of land plants namely tobacco, liverwort, rice and maize (Shinozati et al 1986; Ohyama et al 1986; Hiratsuka et al 1989; Maier et al 1995) that only a single gene for tRNA ${ }^{\text {Pro }}$ is present in these genomes which has a UGG anticodon. The anticodon of this tRNA ${ }^{\text {Pro }}$, namely UGG, should be able to read only two proline codons CCA and CCG, but not CCU or CCC. Marechal Drouard et al (1993) have proposed that the single plant chloroplast tRNA ${ }^{\text {Pro }}$ (UGG) may be able to read all the four proline $\mathrm{CCN}$ codons in chloroplasts and suggested that a "two out of three mechanism" (only the first two bases of the codon which pair with the anticodon) (Lagerkvist 1978) involving two strong G:C base pairs can operate in chloroplasts allowing tRNA ${ }^{\text {Pro }}$ (UGG) to read all four proline codons. It may therefore, be concluded that this cucumber chloroplast tRNA ${ }^{\text {Pro }}$ (UGG) probably reads all the four proline codons in the chloroplasts.

\section{Acknowledgements}

This work was supported by a grant from the Department of Science and Technology, New Delhi. The award of Senior Research Fellowship by University Grants Commission, New Delhi to SH is gratefully acknowledged.

\section{References}

Hande S 1992 Studies on tRNAs and tRNA genes in Cucumber (Cucumis sativus) chloroplasts, Ph.D, thesis, Indian Institute of Science, Bangalore

Hiratsuka J, Shimada H, Whittier R, Ishibashi T, Sakamoto M, Mori M, Kondo C, Honji Y, Shun C-R, Meng B-Y, Li Y-Q, Kanno A, Nishizawa Y, Hirai A, Shinozaki K and Sugiura M 1989 The complete sequence of the rice (Oryza sativa) chloroplast genome: intermolecular recombination between distinct tRNA genes accounts for a major plastid DNA inversion during the evolution of the cereals- Mol. Gen. Genet. 217 185-194

Jayabaskaran C and Puttaraju M 1993 Fractionation and identification of cytoplasmic tRNAs and structural characterization of a phenylalanine and a leucine tRNA from cucumber hypocotyls Biochem. Mol. Biol. Int. 31 983-995

Jayabaskaran C and Hande S 1995 Variations in the levels of aminoacylation and modified nucleotide content between total tRNAs from chloroplasts and etioplasts in cucumber cotyledons; Plant Growth Regul.1673-81

Keith G 1995 Mobilities of modified ribonucleotides on two-dimensional cellulose thin layer chromatogra phy; Biochimie 77 142-144

Lagerkvist U 1978 "Two out of three": an alternative method for codon reading; Proc. Natl. Acad. Sci. USA 75 1759-1762

Maier R M, Neckermann K, Igloi G L and Kosel H 1995 Complete sequence of the maize chloroplast genome: Gene content, hotspots of divergence and fine tuning of genetic information by transcript editing; J. Mol. Biol. 251 614-628

Marechal-Drouard L, Weil J H and Dietrich A 1993 Transfer RNAs and transfer RNA genes in plants; Annu. Rev. Plant Physiol Mol Biol. 44 13-32

Mubumbila M, Burkard G, Keller M, Steinmetz A, Crouse E J and Weil J H 1980 Hybridization of bean, spinach, maize and Euglena chloroplast transfer RNAs with homologues and heterologous chloroplast DNA. An approach to the study of homologies between chloroplast tRNAs from various species; Biochem. Biophys. Acta 609 31-39 
Ohyama K, Fukuzawa H, Kohchi T, Shirai H, Sano T, Sano S, Umesono K, Shiki Y, Takeuchi M, Chang Z, Aota S-T, Inokuchi H and Ozeki H 1986 Chloroplast gene organization deduced from complete sequence of liverwort Marchantia polymorpha chloroplast DNA; Nature (London) 322 572-574

Persson B 1993 Modification of tRNA as a regulatory device; Mol. Microbiol. 8 1011-1016

Shinozaki K, Ohme M, Tanaka M, Wakasugi T, Hayashida N, Matsubayashi T, Zaita N, Chunwongse J, Obokata J, Yamaguchi-Shinozaki K, Ohto C, Torazawa K, Meng B Y, Sugita M, Deno H, Kamogashira T, Yamada K, Kusuda J, Takaiwa F, Kato A, Thodoh N, Shimada H and Sugiura M 1986 The complete nucleotide sequence of the tobacco chloroplast genome: Its gene organization and expression; EMBO J. 5 2043-2049

Sprinzl M, Hartmann T, Weber J, Blank J and Zeidler R 1989 Compilation of tRNA sequences and sequences of tRNA genes; Nucleic Acids Res. (Suppl.) 17 rl-rl72 